Revista Brasileira de História \& Ciências Sociais - RBHCS

Vol. 13 No 26, Janeiro - Junho de 2021

\title{
As dificuldades de mobilidade dos povos originários venezuelanos de etnia Warao no Brasil decorrentes do veto na lei de migrações à sua livre circulação
}

\section{Las dificultades de movilidad de los pueblos originarios venezolanos de etnia Warao en Brasil debido al veto en la ley de migraciones a su libre circulación}

Tatiana Squeff

Julia Pecker**

Resumo: A Lei de Migrações de 2017 é um marco regulatório importantíssimo para a assecuração dos direitos humanos dos migrantes no Brasil. No entanto, um princípio que era de suma importância para a realização de seus objetivos era a previsão da livre circulação indígena transfronteiriça, a qual, porém, restou de fora do texto final em função de um veto presidencial quando da sua sanção, sob o argumento de ser uma ameaça à segurança nacional. Assim, partindo de uma abordagem hipotético-dedutiva e seguindo os métodos de análise analíticodescritivo e explicativo, argumenta-se neste estudo que esse veto não só é ilegal à luz do direito constitucional e internacional, como também é responsável pelas dificuldades encontradas pelos migrantes indígenas venezuelanos de etnia Warao no Brasil. Ao cabo, realizada uma pesquisa monográfica através dos procedimentos bibliográfico e documental, conclui-se que, sim, os Warao são impedidos de manifestar as suas tradições e identidade cultural no país de forma plena forte no aludido veto, clamando-se, consequentemente, pela criação de políticas migratórias voltadas a essa população específica.

Palavras-chave: Lei de Migrações. Indígenas Warao. Livre Circulação.

Resumen: La Ley de Migración de 2017 es un marco regulatorio extremadamente importante para garantizar los derechos humanos de los migrantes en Brasil. Sin embargo, un principio que fue de suma importancia para la realización de sus

\footnotetext{
* Professora permanente do Programa de Pós-Graduação em Direito da Universidade Federal de Uberlândia.Doutora em Direito Internacional pela UFRGS, com período sanduíche junto à Universidade de Ottawa.

*** Pós-graduada em Direito Internacional pela Universidade Federal do Rio Grande do Sul (UFRGS). Graduada em Direito pela Fundação Escola Superior do Ministério Público (FMP/RS).
} 
Revista Brasileira de História \& Ciências Sociais - RBHCS

Vol. 13 No 26, Janeiro - Junho de 2021

objetivos fue la provisión de la libre circulación indígena transfronteriza, que, sin embargo, quedó fuera del texto final debido al veto presidencial cuando fue sancionado, bajo el argumento de ser una amenaza para la seguridad nacional. Así, partiendo de un enfoque hipotético-deductivo y siguiendo los métodos de análisis analítico-descriptivo y explicativo, se argumenta en este estudio que este veto no solo es ilegal bajo el derecho constitucional e internacional, sino que también es responsable de las dificultades que enfrentan los migrantes. Pueblo indígena venezolano de etnia Warao en Brasil. Al final, realizada una investigación monográfica a través de procedimientos bibliográficos y documentales, se concluye que, sí, a los Warao se les impide expresar de manera contundente sus tradiciones e identidad cultural en el país en el mencionado veto, alegando, en consecuencia, por la creación de políticas migratorias dirigidas a esta población específica.

Palabras-clave: Ley de Migraciones. Indígenas Warao. Libre Circulación.

\section{INTRODUÇÃO}

A Lei de Migrações, aprovada em abril de 2017 após diversas propostas legislativas voltadas a substituir o então existente Estatuto do Estrangeiro - ato normativo forjado sob os auspícios da ditadura cívico-militar brasileira marcadamente excludente - representou um avanço expressivo no marco regulatório pátrio sobre o tema. Isso porque, ela trouxe consigo outro paradigma para nortear a dinâmica migratória nacional, qual seja, os direitos humanos, adequando-se, assim, não só à Constituição Federal de 1988, como também aos desenvolvimentos normativos do plano internacional, os quais, desde a metade do Século XX, voltam-se à proteção da pessoa humana em detrimento da soberania estatal.

Assim sendo, dentre os avanços trazidos pela Lei de Migrações estão uma série de direitos humanos dos migrantes e visitantes os quais não só não podem ser afastados pelo Estado brasileiro, como também devem ser objeto de medidas que visem a sua defesa. Relacionado a isso, pode-se dizer que um destaque do Projeto de Lei final, aprovado no Congresso Nacional, foi justamente a garantia da livre 
Revista Brasileira de História \& Ciências Sociais - RBHCS

Vol. 13 No 26, Janeiro - Junho de 2021

circulação do migrante no território nacional e por entre as fronteiras nacionais este no caso específico dos migrantes indígenas transfronteiriços. Tal avanço, segundo as justificativas da comissão de especialistas ${ }^{1}$ apontada pelo Ministério da Justiça para elaborar uma proposta de Anteprojeto para uma nova Lei de Migrações brasileira, centravam-se justamente na necessidade de assegurar aos migrantes indígenas a possibilidade de os mesmos manifestarem a sua cultura e tradições de maneira livre, independentemente da fronteira geograficamente definida pelo colonizador europeu, em alusão a própria plurietnia e multiculturalidade que o Brasil (diz) sustenta(r) em sua Carta Política.

Outrossim, dentre outras questões, a livre circulação indígena por entre as fronteiras foi vetada pelo então Presidente da República, Michel Temer, sob o argumento de ser uma ameaça à segurança do Estado-Nação, sendo esse o tema central do presente artigo. Pontualmente, almeja-se verificar como o citado veto influencia a mobilidade dos migrantes indígenas venezuelanos de etnia Warao no Brasil. A hipótese a ser verificada é, nomeadamente, se as dificuldades encontradas por esse grupo de migrantes transfronteiriços em manifestar a sua cultura de forma plena no Brasil podem ser atribuídas ao veto.

Por isso, inicialmente, faz-se um resgate acerca da adoção do veto e da ilegalidade desta medida, seja em função da própria Constituição de 1988, seja em relação aos diversos documentos e jurisprudências internacionais, as quais terminam por sustentar a invisibilidade indígena no Brasil e que, consequentemente, lhes causam inúmeras dificuldades, como é o caso dos Warao. Desta forma, em um segundo momento, discorre-se especificamente sobre a vinda deste grupo de migrantes ao Brasil e a forma com que o veto ao $\$ 2^{\circ}$ do art. $1^{\circ}$ da Lei de Migrações - onde estava situada a livre circulação de indígenas transfronteiriços - impôs limitações ao seu modo de vida e s sua identidade cultural.

E para atingir tais fins, frisa-se que a metodologia a ser utilizada nessa pesquisa de cunho monográfico é o método de abordagem hipotético-dedutivo, vez que se parte de uma premissa geral (de que as dificuldades de mobilidade dos

${ }^{1}$ Os nove membros da comissão de especialistas apontados pela Portaria $\mathrm{n}^{0}$ 2.162, de 2013, do Ministério da Justiça foram: André de Carvalho Ramos, Aurélio Veiga Rios, Clèmerson Merlin Clève, Deisy de Freitas Lima Ventura, José Luis Bolzan de Morais, Pedro de Abreu Dallari, Rossana Rocha Reis, Tarcíso Dal Maso Jardim e Vanessa Oliveira Berner (CONSULTOR JURÍDICO, 2013). 
Revista Brasileira de História \& Ciências Sociais - RBHCS

Vol. 13 No 26, Janeiro - Junho de 2021

povos originários venezuelanos de etnia Warao no Brasil decorrem do veto presidencial) para a análise de argumentos específicos (da ilegalidade do veto consoante o direito interno e internacional e do consequente tratamento conferido aos migrantes Warao no país). Ademais, quanto a análise dos objetivos, esta seguirá o modelo analítico-descritivo e explicativo: o primeiro especialmente quanto aos propósitos da Lei de Migrações e a ilegalidade do veto, e o segundo quanto à relação entre o veto e as dificuldades enfrentadas pelos migrantes Warao no Brasil. Por fim, tem-se que a presente pesquisa é realizada através dos procedimentos bibliográfico e documental, mais especificamente por textos acadêmicos, bem como com coleta de dados oficiais do governo brasileiro e de agências internacionais, como Organização Internacional para as Migrações e Alto comissariado das Nações Unidas para Refugiados - todos qualitativamente selecionados desde um recorte temático.

\section{O VETO PRESIDENCIAL AO DISPOSITIVO QUE PERMITIRIA A LIVRE CIRCULAÇÃO DE POVOS ORIGINÁRIOS PELAS FRONTEIRAS}

A vida dos não-nacionais que se encontravam em território brasileiro foi regulada durante 34 anos pelo Estatuto do Estrangeiro (Lei $\mathrm{n}^{\circ}$ 6.815, de 1980). Mesmo com a promulgação da Constituição de 1988, o Estatuto permaneceu aplicável, apesar de revelar-se incompatível com a Carta Magna em diversos dispositivos.

Fruto de anos de debates e propostas, a Lei de Migrações (Lei ${ }^{0}$ 13.445, de 2017) finalmente foi aprovada em abril de 2017 e sancionada em maio de 2018 pelo então Presidente da República Michel Temer (MDB-SP) (COELHO; SPESSOTTO, 2017). Com ela, foi restaurada a esperança de possibilitar que o migrante em território brasileiro conseguisse exercer plenamente seus Direitos Humanos (DUPAS; BOTELHO, 2017, p. 80), o que não ocorria quando da vigência do Estatuto do Estrangeiro devido ao seu caráter ultranacionalista e protecionista (KENICKE, 2016, p. 13). 
Revista Brasileira de História \& Ciências Sociais - RBHCS

Vol. 13 No 26, Janeiro - Junho de 2021

A nova legislação, a princípio, abandonava a visão de que o "estrangeiro"2 seria uma ameaça à segurança nacional, prometendo garantir aos imigrantes direitos como liberdade, igualdade, acesso aos serviços públicos e aos direitos trabalhistas, dentre tantos os outros. Os artigos $3^{\circ}$ e $4^{\circ}$ da Lei estabelecem diversos princípios e diretrizes de como o migrante deverá ser tratado quando em território nacional3 (BRASIL, 2017b). Wermuth (2020, p. 105-106) afirma que estes princípios e diretrizes evidenciaram uma nítida "guinada democrática" em como o Brasil passou a olhar para a temática das migrações internacionais, deixando para trás a ideia autoritária de "segurança nacional".

Outrossim, alguns importantes avanços constantes no projeto de Lei foram perdidos em função de vetos do Presidente brasileiro à época (VEDOVATO; ASSIS, 2018, p. 603-604).4 Para os fins do presente texto, destaca-se o veto ao reconhecimento à livre circulação dos povos indígenas em terras de ocupação originária.

A redação inicial da Lei, além de pensar na regulamentação daqueles que atravessam as fronteiras, também considerava aqueles que circulam dentre elas por reconhecerem tal espaço como seu, ignorado as fronteiras geográficas impostas pelos colonizadores europeus. Neste sentido, o projeto da Lei de Migrações, em seu art. $1^{\mathrm{o}}, \S 2^{\mathrm{o}}$, garantia que seriam "plenamente garantidos os direitos originários dos povos indígenas e das populações tradicionais, em especial o direito à livre circulação em terras tradicionalmente ocupadas" (BRASIL, 2017a). Infelizmente, tal dispositivo não se tornou uma realidade, tendo sido um dos 30 dispositivos vetados por Michel Temer (YAMADA, 2017a). Sobre este veto específico, o argumento foi o seguinte:

\footnotetext{
${ }^{2}$ Acerca deste termo, importa considerarmos que "[...] migrar é um direito humano. Qualquer um de nós já migrou ou pode migrar um dia. O verbo do estrangeiro é estar, não ser. No fundo, o estrangeiro não existe, ou somos nós mesmos, por vezes até em nossa pátria" (VENTURA; ILLES, 2012).

3 Além de ter inovado regulando também sobre o emigrante brasileiro, mormente em seu Capítulo VII (BRASIL, 2017b).

4 Foram vetados dispositivos como o da anistia aos que entraram no Brasil até julho de 2016; o da livre circulação de indígenas e populações originárias por entre as fronteiras; e o da dispensa de serviço militar de brasileiros por opção ou naturalizados que já tenham cumprido suas obrigações militares no país de origem (BRASIL, 2017b).
} 
Revista Brasileira de História \& Ciências Sociais - RBHCS

Vol. 13 No 26, Janeiro - Junho de 2021

O dispositivo afronta os artigos $1^{\circ}, \mathrm{I} ; 20, \S 2^{\circ}$; e 231 da Constituição da República, que impõem a defesa do território nacional como elemento de soberania, pela via da atuação das instituições brasileiras nos pontos de fronteira, no controle da entrada e saída de índios e não índios e a competência da União de demarcar as terras tradicionalmente ocupadas, proteger e fazer respeitar os bens dos índios brasileiros (BRASIL, 2017a).

Yamada (2017) observa que o veto visava prejudicar os que, sem dúvidas, não eram estrangeiros no Brasil: os povos indígenas. Ainda, assevera a autora ter sido esta uma tentativa de ampliar a criminalização dos povos indígenas transfronteiriços por meio da criação de "situações de ilegalidades artificiais", afinal, se a livre circulação seria um princípio norteador da nova política migratória nacional5, consoante aduz o art. 3, inc. XIV, da Lei, além da viabilização deste direito, nomeadamente para o residente fronteiriço, ser objeto de especial atenção nos termos do art. 23 (BRASIL, 2017b), impedir o trânsito indígena, além de desproporcional, seria um verdadeiro contrassenso.

Há quem, inclusive, diga que essa condição impõe os indígenas fronteiriços uma condição de discriminação em relação aos migrantes que se dirigem ao Brasil: “quando o Estado garante aos migrantes e refugiados a livre circulação e nega aos indígenas e aos povos tradicionais o que se está a fazer é valorar de forma diferente quais vidas podem e não podem se beneficiar de tal direito" (DUPAS; BOTELHO, 2017, p. 86). Ação essa que, aliás, não só é ilegal à luz das próprias normas pátrias que repudiam a discriminação no art. 3, inc. II (BRASIL, 2017b) e no chapeau do art. $5^{\circ}$ da Constituição (BRASIL, 1988), mas que também é inadmissível consoante a Corte Interamericana de Direitos Humanos (CtIDH) ${ }^{6}$, cujos pareceres indicam o

5 Um resgate histórico sobre as diversas políticas migratórias adotadas no e pelo Brasil desde 1500, consultar: FRAZÃO, 2018; e SEYFERTH, 2002.

6 A Corte já expressou que: “[o]s Estados [...] não podem discriminar ou tolerar situações discriminatórias em detrimento dos migrantes. Entretanto, o Estado sim pode conceder um tratamento distinto aos migrantes documentados a respeito dos imigrantes indocumentados, ou entre migrantes e nacionais, sempre que esse tratamento diferenciado seja razoável, objetivo, proporcional, e não lese os direitos humanos (CtIDH, 2003, para. 119 - grifos nossos); ademais, que "[n]o habrá [...] discriminación si una distinción de tratamiento está orientada legítimamente, es decir, si no conduce a situaciones contrarias a la justicia, a la razón o a la naturaleza de las cosas. De ahí que no pueda afirmarse que exista discriminación en toda diferencia de tratamiento del Estado frente al individuo, siempre que esa distinción parta de supuestos de hecho sustancialmente diferentes y que expresen de modo proporcionado una fundamentada conexión entre esas diferencias y los objetivos de la norma, los cuales no pueden apartarse de la justicia o de la razón, vale decir, no pueden perseguir fines arbitrarios, caprichosos, despóticos o que de 
Revista Brasileira de História \& Ciências Sociais - RBHCS

Vol. 13 No 26, Janeiro - Junho de 2021

comportamento igualitário a ser conferido no plano internacional a todo e qualquer migrante, indígena ou não.

Ademais, ao invocar a defesa do território nacional como elemento de soberania7, resta evidente o resquício do princípio basilar do obsoleto Estatuto do Estrangeiro, ignorando aqueles que deveriam guiar a Lei de Migrações, como a universalidade, indivisibilidade e interdependência dos direitos humanos (BRASIL, 2017b, art. 3, inc. I) - princípios esses que foram cirurgicamente inseridos na legislação ordinária, a fim de terminar com quaisquer dúvidas acerca de uma eventual não-obrigatoriedade do Estado em garantir tais direitos aos migrantes e, assim, ir ao encontro dos fundamentos norteadores da Constituição de 1988 (GUERRA, 2017, p. 1718).

Desta feita, o que era almejado como um avanço legislativo, acabou por tornar-se uma afronta aos direitos dos povos indígenas transfronteiriços, ferindo diretamente seus direitos humanos na medida em que não é possível submeter os mesmos a um Estado-Nação tradicional, colonial e unitário sem que suas particularidades sejam violadas tal como se deu ao longo da história (GOMES, 2018, p. 22), notadamente quando essas relacionam-se com o seu modo de vida (CtIDH, 2001, para. 138; CtIDH, 2007, paras. 57 e 178) ${ }^{8}$.

Como dia Silva (2013, p. 25), a "existência dos povos indígenas transcende historicamente a existência do Estado-Nação"9. Há pelo menos 178 terras indígenas localizadas em faixa de fronteira do Brasil, as quais, como observa Ferrari (2012), podem ser consideradas "zonas de incerteza identitária10", não havendo que se falar

alguna manera repugnen a la esencial unidad y dignidad de la naturaleza humana" (CtIDH, 1984, para. 57 - grifos nossos).

7 Importa avultar o pensamento de Yamada (2017), para quem não há contradição entre liberdade de locomoção indígena transfronteiriça e soberania, vez que "é exatamente a presença de povos indígenas na zona de fronteira a razão histórica, e atual, da garantia da paz e da soberania nacional em muitos rincões do Brasil" na medida em que eles contestam as invasões e grilagens de terra, a extração ilegal de madeira e de minério e, até mesmo, o tráfico de drogas e de armas.

8 Para um debate acerca das obrigações dos Estado em criar mecanismsos para resguardar a diversidade cutlrual e a pluralidade de etnias dentro de sua jurisdição no âmbito da CtIDH, $c f$. SQUEFF, 2016, p. 58-60.

9 O autor continua: "Ou seja, os povos indígenas já existiam muito antes do surgimento do Estado, sobreviveram à globalização destas unidades políticas, e seguramente continuarão a existir após as possíveis transformações, o declínio ou o desaparecimento da entidade política do Estado-Nação e de seus sistemas" (SILVA, 2013, p. 25).

10 "[...] No entanto, podemos pensar que, em zonas de fronteira, os fronteiriços promovem a mescla, não carregando valores de uma única identidade nacional. $\mathrm{E}$ o fato de estudar ou ter registro de 
Revista Brasileira de História \& Ciências Sociais - RBHCS

Vol. 13 No 26, Janeiro - Junho de 2021

muitas vezes em 'brasileiro' (ou mesmo 'venezuelano'), senão de um indivíduo de uma determinada etnia indígena, cujo território habitado possivelmente vai além das fronteiras políticas impostas pelos colonizadores, culminando no estabelecimento de relações familiares em “diversos países” (YAMADA, 2017a).

Com isso, mesmo que tenha sido um ato puramente político (SESTOKAS, 2017), o veto em comento evidencia a violação do Estado às próprias garantias constitucionais e aos acordos internacionais de proteção relativos à causa indígena e aos povos tradicionais (GOMES, 2018, p. 22; DUPAS; BOTELHO, 2017, p. 81). No que tange o primeiro, é possível dizer que o veto fere o preceito constitucional invocado na sua própria justificativa, uma vez que o art. 231 da Carta Magna traz que deverão ser reconhecidos e respeitados "os direitos originários sobre as terras que tradicionalmente ocupam" (BRASIL, 1988). ${ }^{11}$ Assim, o veto à livre circulação evidencia o desrespeito do Estado à estrutura de vida e territorial, às tradições e à dignidade destes povos (DUPAS; et. al., 2017, p. 15).

Já em relação ao segundo, impende relembrar o reconhecimento internacional do direito de circulação de povos indígenas transfronteiriços na Convenção no 169 da OIT sobre Povos Indígenas e Tribais de 1989, ratificada pelo Brasil em 2002 e promulgada em 2004 por meio do Decreto n. 5.051 (hoje, substituído pelo Decreto n. 10.088/19). Nela, é preceituada a universalidade de direitos indígenas, indicando que o Estado deverá ter medidas de proteção aos seus direitos, e que devem ser respeitadas suas vidas, crenças, instituições e bem-estar espiritual, dentre outros (BRASIL, 2019).

$\mathrm{O}$ seu artigo $3^{\circ}$ indica que "os povos indígenas e tribais deverão gozar plenamente dos direitos humanos e liberdades fundamentais [...]"; e o seu art. $4^{\circ}$ preceitua que "deverão ser adotadas as medidas especiais que sejam necessárias para salvaguardar as pessoas, as instituições, os bens, as culturas e o meio

nascimento e falar a língua do vizinho não determina o fortalecimento de uma identidade nacional" (FERRARI, 2012, p. 94).

${ }^{11}$ A relevância da introdução do art. 231 na Constituição de 1988 é destaque na análise de Squeff e Monteiro (2018, p. 74): "As far as the right to cultural diversity is concerned, because Brazil is a multicultural country, the Brazilian Federal Constitution of 1988 has introduced in its article 231 the recognition of cultural plurality and multi-ethnicity, in order to guarantee the obligation of state power to respect and protect the cultural, economic and social rights of indigenous communities" (grifos nossos). 
Revista Brasileira de História \& Ciências Sociais - RBHCS

Vol. 13 No 26, Janeiro - Junho de 2021

ambiente dos povos interessados", ainda aduzindo que "tais medidas especiais não deverão ser contrárias aos desejos expressos livremente pelos povos interessados" (BRASIL, 2019), o que, note-se, se tornou um obstáculo após o veto.

Além disso, a Declaração das Nações Unidas sobre Povos Indígenas de 2007 - apoiada pelo Brasil e por outros 147 países (YAMADA, 2017b) - assegura diversos direitos aos indígenas, como o de "manter e desenvolver contatos, relações e cooperações tradicionais, incluindo intercâmbio cultural, social e comercial, com seus próprios parentes e amigos, através das fronteiras estatais e a obrigação de o Estado adotar medidas para facilitar tais contatos" (NAÇÕES UNIDAS, 2007) mais um reconhecimento internacional no qual se evidencia a incompatibilidade com o veto presidencial.

Ato contínuo, outro documento que teve seu bojo frustrado pelo veto em apreço fora a Declaração Americana sobre os Direitos dos Povos Indígenas (DADPI), arquitetada em 2016 a fim de promover e proteger os direitos dos povos indígenas das Américas. Muito embora seja um soft law, seu art. XXVI dispõe "o dever dos Estados de reconhecer, respeitar e proteger as terras, os territórios, o meio ambiente e as culturas [dos] povos [indígenas]", o que contemplaria a própria livre circulação quando lido em concomitância aos arts. III e XIIII, se esta for uma característica elementar de certa comunidade indígena12 (FUNAI, 2016; CURY; DIAS, 2019, p. 10-11).

Além disso, o ato brasileiro também estaria desconsiderando a própria jurisprudência internacional. A Corte Internacional de Justiça, em março de 2013, em um caso paradigmático, decidiu sobre a disputa fronteiriça entre Burkina Faso e Níger, local habitado por populações nômades e seminômades. Na decisão, a Corte ressaltou que deveriam ser levadas em conta as condições de vida das populações locais (CIJ, 2013, para. 112) ${ }^{13}$, as quais faziam impossível a separação

12 RODRIGUES et al. (2019, p. 111 e 113-114) apontam que o Brasil rotineiramente desconsidera o direito dos povos tradicionais à livre mobilidade e, logo, as conotações à terra introduzidas pelas próprias comundiades, em especial, o reconhecimento deste espaço para além de uma "simples ocupação da terra para explorá-la, mas base de seu habitat, no sentido ecológico de interação do conjunto de elementos naturais e culturais que propiciam o desenvolvimento equilibrado da vida humana".

13 Deve-se, ainda, mencionar igualmente a interpretação do julgado Preah Vihear Temple, entre Camboja e Tailândia, feito pela CIJ em 2011 (ICJ, 2011, paras. 60 e 77). Para um comentário sobre esse caso, $c f$. RODRIGUES et al., 2019, p. 123 e SIMIONI; VEDOVATO, 2018, p. 305. 
Revista Brasileira de História \& Ciências Sociais - RBHCS

Vol. 13 No 26, Janeiro - Junho de 2021

entre povo e território, de modo que seria inapropriado "desconsider[ar-se] um para se fixar o outro" (SIMIONI; VEDOVATO, 2018, p. 305).

Esse entendimento, logo, faz com que não seja possível sustentar-se a soberania estatal quando se tenha como reflexo a proibição de circulação por entre as fronteiras justamente por ser essa uma característica de tais povos, sendo, assim, necessário considerar o fator humano. Inclusive, acerca disso, Trindade (2014), ao comentar sobre o caso, aduziu que "os Estados têm fins humanos: acima da soberania estatal, a lição básica deste caso está centrada na solidariedade humana, no mesmo nível que a necessária segurança jurídica das fronteiras”, fazendo com que seja imperioso abordar o "tema [...] clássico como o do território [...] conjuntamente com a população" (grifo nosso) - e não separadamente como fez o governo brasileiro ao vetar o $\$ 2^{\circ}$ do art. $1^{\circ}$ da Lei de Migrações.

Assim, apesar de ter havido uma expectativa de livre trânsito dos povos indígenas em seus territórios, esta infelizmente não se tornou realidade devido ao veto realizado pelo então Presidente mdebista, ignorando não só a Constituição, como também as prescrições do Direito Internacional, em especial aquelas que constituem hard law e que, por força disso, deveriam ser executadas pelo Brasil, dificultando mais uma vez a resistência dos povos indígenas que se encontram sob a sua jurisdição e desrespeitando seu modo de vida e sua identidade cultural. Dificuldade essa que resta evidente no caso da circulação dos indígenas de etnia Warao, tal como se discorrerá no próximo item.

\section{A DIFICULDADE DE MOBILIDADE DOS WARAO PARA O BRASIL: REFLEXOS DO VETO AO §2o DO ART. 10 DA LEI DE MIGRAÇÕES}

Nos últimos anos a Venezuela tem perpassado por uma das piores crises de sua história, atingindo diretamente suas esferas política - com o governo de Nicolás Maduro, e econômica - com a desvalorização do petróleo no mercado internacional e a precarização de sua principal estatal PDVSA. Essas duas esferas atingiram uma terceira, acarretando em uma crise humanitária, na qual sua 
Revista Brasileira de História \& Ciências Sociais - RBHCS

Vol. 13 No 26, Janeiro - Junho de 2021

população se desloca para outras nações em busca de melhores condições de vida, após uma grave e generalizada violação de direitos humanos. O Brasil é o sexto país mais procurado por estes migrantes, já tendo recebido mais de 260 mil venezuelanos nos últimos anos $(\mathrm{R} 4 \mathrm{~V}, 2021)$.

As principais dificuldades de recepcionar este fluxo não se dão somente por seu expressivo número de pessoas, mas também por sua variedade étnica, cultural e social (MACHADO et al., 2020, p. 227). Considerável parte de seu contingente é indígena - grupo já sofre historicamente com a invisibilização perante à sociedade (UNHCR, s./d.) e cujos indivíduos estavam com dificuldades no levantamento de recursos necessários para a sua sobrevivência nos centros urbanos da Venezuela (YAMADA et al., 2018, p. 27), além de estarem sofrendo situações de conflito e pressões sobre suas terras e recursos (OIM, 2018, p. 23; SOUSA, 2018, p. 82-83), fazendo-os deslocar por entre as fronteiras.

De toda sorte, independente se indígena ou não, ao migrante venezuelano que adentra o território brasileiro é facultado solicitar o visto de residência ${ }^{14}$ ou a solicitação de reconhecimento da situação de refúgio. A maioria dos indígenas solicita a segunda opção, acreditando se enquadrarem legalmente como indivíduos que emigraram de seu país forçadamente por fundado temor de perseguição de grupo social 15 ou maciça violação de direitos humanos ${ }^{16}$ (ACNUR, 2020a). Dados de setembro de 2020 do Alto Comissariado das Nações Unidas para Refugiados (ACNUR) apontaram a existência de mais de 5 mil indígenas oriundos da Venezuela no Brasil. Destes, 65\% são de etnia Warao e 30\% de etnia Pemón ${ }^{17}$.

\footnotetext{
14 Isto decorre do fato de a Venezuela ser um país fronteiriço integrante do Mercosul - ainda que a mesma esteja atualmente suspensa do bloco.

15 Nos termos do art. 1(2) da Convenção de Genebra de 1951 relativa ao Estatuto do Refugiado, internalizada no Brasil através do Decreto n. 50.215 de 1961 (BRASIL, 1961). Apesar disso, importante ressaltar a dificuldade, por vezes, de conceituar os Warao enquanto refugiados, pois os mesmos, como se demonstrará na sequência do texto, são reconhecidos por movimentar-se, não sendo a impossibilidade/temor de retornar ao seu país de origem - elemento essencial na caracterização de um refugiado nos termos da Convenção de 1951 - uma realidade (SOUSA, 2018, p. 88).

${ }^{16}$ Nos termos da terceira conclusão da Declaração de Cartagena de 1984 (OEA, 1984), a qual, hoje, pode ser compreendida ao menos enquanto costume regional à luz da jurisprudência da CtIDH (2013, para. 141).

17 Os Pemón (Arekuna, Kamarakoto, Taurepang) são o quarto maior grupo de indígenas da Venezuela, contando com uma população de mais de 30 mil pessoas e tendo como língua o Karib. O grupo ocupa a Gran Sabana, correspondente à parte sudeste do estado Bolívar (POVOS INDÍGENAS NO BRASIL, 2004).
} 
Revista Brasileira de História \& Ciências Sociais - RBHCS

Vol. 13 No 26, Janeiro - Junho de 2021

Ainda, há um considerável contingente de indígenas de etnia E'ñepa ${ }^{18}$ (ACNUR, 2020b).

Os Warao são originários do norte da Venezuela, especificamente da região do Delta do Orinoco do Estado Delta Amaruco e regiões adjacentes dos estados Bolívar e Sucre, na Venezuela (PEREIRA, 2019). Os Warao contam com uma população de quase 50 mil pessoas, sendo a segunda maior etnia da Venezuela depois da WayUú. A palavra 'warao' em sua língua nativa significa "gente que navega", sendo, assim, reconhecidos pela sua mobilidade pendular ${ }^{19}$, vez que se movimentam em busca de recursos básicos (SIMÕES, 2017). A garantia do alimento para si e para a sua família que permanecera na Venezuela, assim, apresenta-se enquanto principal fator de mobilidade (MARÉCHAL et al., 2020, p. $58) .{ }^{20}$

A mobilidade dos Warao acontece em grupos, geralmente entre familiares. Sua sociedade é constituída por grandes famílias que mantêm laços de parentesco, agrupando-se em caráter endogâmico ${ }^{21}$ - a autoridade da mulher reflete-se no matriarcado. É considerado como forma de obtenção de recurso o ato de sair às ruas para pedir dinheiro, sendo o mesmo realizado por todo o grupo familiar: mulher, homem e crianças ${ }^{22}$. Há um entendimento cultural diferenciado quanto à infância e à mulher. As mulheres geralmente organizam o deslocamento inicial da

${ }_{18}$ Assim como os Pemón, os E'ñepa falam o Karib. Esta etnia é conhecida por sua cestaria com desenhos geométricos, expostas em diversos museus etnográficos. Possuem seus territórios no estado Bolívar, em áreas de floresta tropical da Venezuela (OIM, 2020, p. 56).

19 "De fato, uma das características dessa etnia é o deslocamento, em alguns períodos do ano, entre comunidades, regiões e cidades, o que tem sido feito tanto pelos braços do Rio Orinoco (caños), quanto a pé, com o objetivo de complementar os recursos necessários para subsistência do grupo" (SILVEIRA; CARNEIRO, 2018, p. 80), de modo que o seu objetivo, uma vez cumprida a sua tarefa, é retornar. Por isso, chama-se de 'movimento pendular'.

${ }^{20}$ Nas palavras dos autores: "A escassez de comida nas comunidades warao [...] é um dos fatores que motivam esses deslocamentos mais recentes, a primeira transnacional de que se tem registro. A alimentação constitui-se, portanto, como um pilar da organização social atual dos Warao, sendo um dos principais argumentos levantados por eles para explicar seus deslocamentos. [...] [N]o Brasil tem muita comida. Então o ideal é que se envie parte dos alimentos para enezuela com a finalidade de sustentar os familiares que permanecem do outro lado da fronteira" (MARÉCHAL et al., 2020, p. 58 e 62).

${ }^{21}$ Quando dois indivíduos se casam por ambos pertencerem à mesma classe e/ou tribo, a fim de preservarem suas raças.

${ }^{22}$ Salienta-se que essa situação, inclusive, gera grandes debates quando do deslocamento desse grupo no interior do Brasil, na medida em que, consoante a lei, esse ato pode dar ensejo a destituição do poder familiar - medida que foi objeto de recomendação por parte do Conselho Nacional dos Direitos Humanos, para que tais crianças não sejam afastadas de suas famílias sem que sejam observadas todas as medidas do Estatuto da Criança e do Adolescente. $C f$. BRASIL, 2019. 
Revista Brasileira de História \& Ciências Sociais - RBHCS

Vol. 13 No 26, Janeiro - Junho de 2021

família, arrecadam fundos para a obtenção de alimentos através da venda de artesanato e do ato de pedir dinheiro nas ruas (OIM, 2018b, p. 16).

Isso decorre do fato de os indígenas desta etnia serem tradicionalmente pescadores e coletores, geralmente vivendo em comunidades de palafitas em zonas ribeirinhas fluviais e marítimas (CASTRO, 2000, p. 79). Originalmente utilizavam da palmeira de buriti como matéria-prima para construírem suas casas, embarcações e artesanatos como redes e utensílios. Simões (2017, p. 16) observou que a maioria dos Warao que migraram para o Brasil relatam que sentem falta das ferramentas de trabalho integradas à natureza, principalmente os buritizais. Ademais, o povo Warao é o único que vincula à sua vivência a um amplo conhecimento das palmeiras (MACHADO et al., 2020, p. 233).

Não há relação de parentesco ou qualquer outro tipo de aliança entre os Warao e os indígenas que habitam o Brasil, fator que dificulta ainda mais sua inserção social no país (SIMÕES, 2017, p. 80). Quanto à motivação desta etnia ter imigrado para o Brasil, o Parecer Técnico no 10/17: SP/MANAUS/SEAP do MPF (2017) analisa:

Os Warao relataram que durante o governo de Hugo Chávez havia políticas públicas voltadas para os povos indígenas na Venezuela, como o repasse de alimentos (trigo, macarrão, açúcar, etc.) para as comunidades na beira dos caños18. No entanto, tais medidas foram interrompidas nos últimos anos. Era comum ouvi-los dizer que atualmente o "governo não chega às comunidades", o que se traduz pela falta de políticas públicas de atendimento à saúde e de assistência social. A ausência de medicamentos nas comunidades era constantemente apontada como uma das causas de mortes nas comunidades, assim como a fome, que já estava vitimando parentes que permaneceram na Venezuela (MPF, 2017, p. 17).

Desta forma, nada mais natural que os mesmos se deslocassem e, uma vez alcançando o Brasil, fossem recebidos através da Operação Acolhida - ForçaTarefa Logística Humanitária lançada pelo Governo Federal em 2018, a fim de recepcionar e acolher humanitariamente os migrantes venezuelanos que chegassem ao país através do estado de Roraima. A Operação consiste em três pilares principais: ordenamento da fronteira, abrigamento e interiorização (SQUEFF, 2019). 
Revista Brasileira de História \& Ciências Sociais - RBHCS

Vol. 13 No 26, Janeiro - Junho de 2021

Nesta segunda fase, avulta-se a existência de dois abrigos específicos para migrantes indígenas, buscando atender suas características únicas. $\mathrm{O}$ primeiro situa-se na cidade fronteiriça de Pacaraima, chamado de Janokoïda²3, onde há áreas específicas para que se mantenham as tradições, como espaço para fogão à lenha e redário (SQUEFF, 2019, p. 134). Em Boa Vista, capital de Roraima, é onde se localiza o segundo, chamado de Pintolândia, onde há espaço exclusivo para a comercialização de artesanato feito pelas mulheres indígenas venezuelanas (ACNUR, 2020c).

Note-se, porém, que a migração vai além do estado de Roraima: há diversos indígenas venezuelanos em outras unidades federativas do Brasil, mormente nos estados do Amazonas (Manaus) e Pará (em especial, em Belém do Pará), muito embora existam relatos de Warao no Maranhão (São Luís), Acre (Rio Branco), Pernambuco (Recife), Minas Gerais (Uberlândia e Juiz de Fora) e Santa Catarina (Itajaí), para citar alguns. Ocorre que nestes locais não há assistência do Governo Federal para os mesmos, vez que as ações de abrigamento para indígenas restam limitadas a Roraima (OIM, 2020, p. 31-36), conduzindo-os a situações de extrema vulnerabilidade social (BARBOSA, 2020a)24-25 e de contínua movimentação nos rincões do país, forte na sua cultura.

E o despreparo por parte das autoridades locais, nesse caso dos migrantes indígenas, é evidente (BARBOSA, 2020b). Desde 2016, a ação mais comum vislumbrada em relação a este grupo foi a de "limpeza social", buscando "tir[á-los] da vista", pois, por serem "considerados como mendicantes, 'sujam' a cidade e se convertem em um novo problema social que o poder público e os representantes do governo [entendem ser o seu dever] enfrentar", gerando "um potente controle social das entradas e saídas dos Warao [das cidades] [...] inclusive antes do surto de Covid-19" (MARÉCHAL et al. 2020, p. 52-53 - grifo nosso), desconsiderando as

\footnotetext{
23 A palavra "Janokoïda" significa "grande casa" em Warao.

$24 \mathrm{Em}$ todas as cidades apontadas os relatos de hipervulnebailidade social dos migrantes Warao são comuns. $C f$. PARAIZO, 2019, SEMINARIO, 2020, PARENTE, 2020, ARAÚJO, 2021, VIEIRA, 2020. 25 "Devido às diferenças culturais, ao emigrarem para os centros urbanos, os Warao passam a exercer atividades destinadas a 'mão de obra de baixa qualificação, ou como pedintes, embora tenham mantido, em ambos os casos, os processos de significação próprios e as redes de relações'. Dessa forma, eles conseguiram recursos para levar ao seu local de origem e auxiliar os outros membros de sua comunidade" (SILVEIRA; CARNEIRO, 2018, p. 78 - grifos nossos).
} 
Revista Brasileira de História \& Ciências Sociais - RBHCS

Vol. 13 No 26, Janeiro - Junho de 2021

suas características intrínsecas de mobilidade transitória e pendular. Por isso, não causa estranheza quando Sousa (2018, p. 88) tece que o

[...] cruzamento da fronteira [pelos Warao] muitas vezes tem sido feito propositalmente por pontos livres de fiscalização da Polícia Federal, de forma que essas pessoas entram no país sem serem documentadas. Esses migrantes entram no Brasil nessa condição principalmente pelo temor da deportação ou impedimento de entrada, já que, em 2014, cerca de 60 pessoas da etnia Warao foram deportadas, e em 2016, houve uma tentativa de deportação de 450 pessoas.

Outrossim, mesmo que a Operação Acolhida tenha facilitado e, em certa medida, humanizado a recepção de Waraos, essa ação resta limitada ao estado de Roraima e não significa o reconhecimento para com a motivação da migração, assim como o caráter temporário que ela apresenta para os migrantes indígenas. Pior ainda é a situação imposta pela Covid-19: haja vista a pandemia ter fomentado o fechamento de fronteiras como forma de contenção do vírus, em especial em relação à Venezuela ${ }^{26}$, nota-se novamente uma desconsideração para com a sua cultura de mobilidade pendular quando em janeiro de 2021, o Brasil tentou deportar 55 pessoas de etnia Warao, dentre as quais haviam grávidas, idosos e 32 crianças, que entravam ilegalmente no país após caminharem cerca de 730 quilômetros durante 18 dias (MERGULHÃO, 2021).

Mesmo que essa ação tenha sido felizmente impedida pela Defensoria Pública da União de Roraima, o que se absorve do ocorrido é justamente a continuidade de uma política de aculturação promovida pelo Estado brasileiro em relação a essa população indígena proveniente da Venezuela. Afinal, apesar do texto constitucional apontar em outra direção, a permanência no país não lhes garante a realização de plena de suas tradições, especialmente pela política de contingenciamento (de mobilidade) e de indiferença (social) implementada por diversos governos municipais e estaduais país afora, como anteriormente relatado.

\footnotetext{
${ }^{26}$ Segundo as portarias interministeriais referentes ao fechamento de fronteiras brasileiras, nenhum não-nacional oriundo da Venezuela está autorizado a entrar no país, o que, por si só, fere o princípio da não-discriminação e do direito de ter a sua situação de refúgio reconhecida. A última portaria editada até a última versão deste artigo fora a de n. 651, de 8 de janeiro de 2021 (BRASIL, 2021).
} 
Revista Brasileira de História \& Ciências Sociais - RBHCS

Vol. 13 No 26, Janeiro - Junho de 2021

Situação essa que, acredita-se, é um reflexo - negativo - da imposição do veto ao $\S 2^{\circ}$ do art. $1^{\circ}$ da Lei de Migrações por parte do então Presidente Temer. Afinal, se houvesse sido promulgado, o Brasil estaria cumprindo para com os documentos nacionais e internacionais apontados na parte um do presente texto ao promover o livre trânsito dos Warao por entre as fronteiras do país junto à Venezuela. De toda sorte, é de se pontuar que, uma vez estando no interior do Estado, deveriam ser estipuladas políticas públicas destinadas à própria defesa e assecuração de sua mobilidade e cultura, forte nos mesmos documentos normativos citados na parte um, vez que eles não assegurariam apenas a mobilidade pendular fronteiriça como igualmente a interna no Estado brasileiro. Assim, demonstra-se cada vez mais imperativo que se pense soluções duradouras culturalmente adequadas ${ }^{27}$ para estes povos específicos.

\section{CONCLUSÃo}

A presente pesquisa pretendia verificar a relação existente entre as dificuldades encontradas por migrantes indígenas de etnia Warao oriundos da Venezuela em manifestar a sua cultura de forma plena no Brasil e o veto realizado ao $\S 2^{\circ}$ do art. $1^{\circ}$ da Lei 13.445 de 2017 pelo então Presidente da República Michel Temer quando da sua sanção. Portanto, o estudo centrou-se no debate de dois tópicos: (a) a da (des)regulamentação da livre circulação das populações indígenas migrantes no Brasil, e (b) a da (des)consideração da cultura dos migrantes indígenas por parte das autoridades pátrias enquanto um reflexo do veto.

Quanto ao primeiro item, expôs-se a relevância da inserção do princípio da liberdade de circulação por entre as fronteiras - e não apenas no interior do Estado brasileiro - na legislação migratória ordinária aprovada em 2017, especialmente por ela se coadunar tanto com os preceitos constitucionais, em especial o art. 231

\footnotetext{
27 "A ideia de solução duradoura se opõe à de atenção emergencial. Se a emergência é o reino da contingência, em que preservar vidas e garantir condições básicas mínimas é a prioridade absoluta, no contexto das soluções duradouras muitas outras variáveis passam a ser consideradas, pensando nas perspectivas de vida futuras dos migrantes e refugiados e de suas comunidades de acolhida" (OIM, 2020, p. 21).
} 
Revista Brasileira de História \& Ciências Sociais - RBHCS

Vol. 13 No 26, Janeiro - Junho de 2021

da Constituição de 1988, o qual promove a proteção integral dos povos originários através do reconhecimento de suas culturas e tradições ao lado dos demais povos que se encontram no Estado, quanto aos documentos internacionais que o Brasil é parte, notadamente a Convenção n. 169 da OIT por estabelecer deveres aos Estados em assegurar os direitos dos povos originários, incluindo-se as suas manifestações culturais e identitárias, e os diversos precedentes internacionais que apontam para a não-discriminação entre migrantes (Corte Interamericana de Direitos Humanos) e para a impossibilidade de desconsiderar-se o território apartado da questão humana (Corte Internacional de Justiça).

Regras essas que foram abertamente desconsideradas quando do veto ao $\S 2^{\circ}$ do art. $1^{\mathrm{o}}$ da Lei 13.445 de 2017 e que culminaram na sustentação de uma desregulamentação da livre circulação transfronteiriça, cuja consequência é justamente a confirmação da ilegalidade em torno dessa mobilidade indígena quando realizada por rotas irregulares, as quais são a opção mais utilizada pelos Warao quando cruzam a fronteira política historicamente imposta em direção ao Brasil e que culminam na desconsideração de sua cultura por parte das autoridades pátrias. Designadamente, aponta-se para a desconsideração da mobilidade transitória pendular enquanto elemento intrínseco do modo de vida deste povo, na medida em que, o que os mesmos buscam, são recursos para a sua subsistência e a de sua família, esteja ela no Brasil ou na Venezuela - e não um novo lugar para se estabelecerem de maneira fixa e permanente.

Na medida em que o povo Warao é migrante por sua natureza, ao proibir a sua livre circulação, o seu modo de vida foi afetado diretamente. Desta forma, entende-se que a legislação da forma como foi sancionada deixou uma brecha para a desassistência dos migrantes indígenas, recepcionando-os de forma semelhante aos demais migrantes venezuelanos não-indígenas, sem levar em consideração as diferenças étnicas e culturais e dificultando ainda mais a sua acolhida e inserção na sociedade brasileira. Afinal, os Warao são submetidos a situações de extrema vulnerabilidade social e de contínua exclusão econômica, social e moral, sobretudo, quando situados em um contexto urbano, muito em razão do desconhecimento por 
Revista Brasileira de História \& Ciências Sociais - RBHCS

Vol. 13 No 26, Janeiro - Junho de 2021

parte das autoridades de suas tradições e características enquanto um povo tradicionalmente nômade.

Ainda que a Operação Acolhida tenha criado algumas medidas que visam garantir a preservação de sua cultura e de seu modo de viver, o veto segue sendo bastante prejudicial. A falta de regulamentação para migrantes indígenas no Brasil, inclusive, acaba por abrir portas para situações como as recorrentes tentativas de deportação de indígenas Warao, indiferentemente de estar-se em um contexto pandêmico ou não.

Nesse passo, considerando a existência do veto, entende-se ser necessária a criação de políticas migratórias voltadas a essa população específica, respeitando suas culturas e tradições, e demandando soluções diferenciadas de médio e longo prazo. Até mesmo porquê, para além de ser um tema da esfera constitucional, é também uma pauta supralegal e sujeita ao controle de convencionalidade, haja vista que o Brasil é parte da Convenção 169 da OIT, assim como deve observar os precedentes internacionais sobre o tema - em especial àqueles concernentes aos direitos humanos, forte não só no art. 4, inc. II (prevalência dos direitos humanos) e III (autodeterminação dos povos) da Constituição Federal que regulamenta as relações internacionais do Estado brasileiro (BRASIL, 1988), como também no §2 ${ }^{\circ}$ do art. $5^{\circ}$, uma clausula pétrea que impõe a observância dos direitos e garantias oriundos do Direito Internacional.

\section{REFERÊNCIAS BIBLIOGRÁFICAS}

ACNUR. Relatório do ACNUR revela que 65\% dos indígenas venezuelanos registrados no Brasil são solicitantes de refúgio. UNHCR, 03 jun. 2020a. Disponível em: <https://www.acnur.org/portugues/2020/06/o3/relatoriodo-acnur-revela-que-maioria-dos-indigenas-venezuelanos-registrados-no-brasil-saosolicitantes-de-refugio/>. Acesso em: 02 fev. 2021.

. Relatório de Atividades para Populações Indígenas. UNHCR, set. $2020 b$. Disponível em: <https://r4v.info/es/documents/details/82592>. Acesso em: 02 fev. 2021.

. Espaço para venda de artesanato de indígenas venezuelanos é inaugurado em Boa Vista. UNHCR, 30 out. 2020c. Disponível em: <https://www.acnur.org/portugues/2020/10/30/espaco-para-venda-de-artesanato- 
Revista Brasileira de História \& Ciências Sociais - RBHCS

Vol. 13 No 26, Janeiro - Junho de 2021

de-indigenas-venezuelanos-e-inaugurado-em-boa-vista/>. Acesso em: o5 fev. 2021.

ARAÚJO, Marcos. Presença de venezuelanos nas ruas de Juiz de Fora preocupa autoridades. Tribuna de Minas, s./l., 07 jan. 2021. Disponível em: https://tribunademinas.com.br/noticias/cidade/o7-01-2021/presenca-devenezuelanos-nas-ruas-de-juiz-de-fora-preocupa-autoridades.html

BARBOSA, Catarina. Indígenas Warao: os desafios da migração e as dificuldades da vida no Brasil. Brasil de Fato, Belém, 25 ago. 2020a. Disponível em: https://www.brasildefato.com.br/2020/o8/25/indigenas-warao-os-desafios-damigracao-e-as-dificuldades-da-vida-no-brasil. Acesso em: 06 fev. 2021

- Indígenas Warao sofrem com péssimas condições de vida no abrigo público de Belém. Brasil de Fato, Belém, 26 ago. 2020b. Disponível em: https://www.brasildefato.com.br/2020/o8/26/indigenas-warao-sofrem-compessimas-condicoes-de-vida-no-abrigo-publico-de-belem. Acesso em: 06 fev. 2021

BRASIL. Legislação Informatizada - Lei No 13.445, de 24 de maio de 2017 - Veto. Brasília, 25 mai. 2017 a.

. Lei no 13.445, de 24 de maio de 2017. Lei de Migrações. Brasília, 24 mai. 2017b.

. Constituição da República Federativa do Brasil de 1988. Brasília, O5 out. 1988.

Decreto no 10.088, de o5 de novembro de 2019. Consolida atos normativos editados pelo Poder Executivo Federal que dispõem sobre a promulgação de convenções e recomendações da Organização Internacional do Trabalho - OIT ratificadas pela República Federativa do Brasil. Brasília, o5 de novembro de 2019.

. Decreto n. 50.2015 de 28 de janeiro de 1961. Promulga a Convenção relativa ao Estatuto dos Refugiados, concluída em Genebra, em 28 de julho de 1951. Disponível em: https://www2.camara.leg.br/legin/fed/decret/1960-1969/decreto50215-28-janeiro-1961-389887-publicacaooriginal-1-pe.html. Acesso em: 07 fev. 2021

. Portaria n. 651 de 8 de janeiro de 2021. Dispõe sobre a restrição excepcional e temporária de entrada no País de estrangeiros, de qualquer nacionalidade, conforme recomendação da Agência Nacional de Vigilância Sanitária - Anvisa. Disponível em: https://www.in.gov.br/en/web/dou/-/portarian-651-de-8-de-janeiro-de-2021-298262949. Acesso em: 06 fev. 2021

. CNDH. Recomendação n. 20 de 10 out. 2019. Disponível em: https://www.gov.br/mdh/pt-br/acesso-a-informacao/participacao- 
Revista Brasileira de História \& Ciências Sociais - RBHCS

Vol. 13 No 26, Janeiro - Junho de 2021

social/conselho-nacional-de-direitos-humanos-

cndh/Recomendaon2oCrianasWarao.pdf. Acesso em: 13 nov. 2020

CASTRO, Alvaro A. G.. Mendicidad indígena: Los Warao Urbanos Boletín

Antropológico n. 48. Jan.-abr. 2000, ISSN: 1325-2610. Mérida, Venezuela: Centro de Investigaciones Etnológicas. Museo Arqueológico - Universidad de Los Andes. P. 79-90.

CIDH. Opinião Consultiva o4/84. Exarada em 19 de janeiro de 1984. Disponível em: https://www.corteidh.or.cr/docs/opiniones/seriea_04_esp.pdf. Acesso em: 07 fev. 2021

. Opinião Consultiva 18/o3. Exarada em 17 de setembro de 2003. Disponível em: https://www.cnj.jus.br/wpcontent/uploads/2016/04/58a49408579728bd7f7a6bf3fıf80051.pdf. Acesso em: o7 fev. 2021.

\begin{tabular}{ccccc}
\multicolumn{4}{c}{ Caso Família Pacheco Tineo vs. Estado Plurinacional da Bolívia. } \\
Sentença & de & 25 & nov. & 2013.
\end{tabular} https://www.corteidh.or.cr/docs/casos/articulos/seriec_272_ing.pdf. Acesso em: O7 fev. 2021.

de $2007 . \quad$ Disponível 2 em: htps://www.cnj.jus.br/wpcontent/uploads/2016/04/cc1a1e511769096f84fb5effe768fe8c.pdf. Acesso em: o7 fev. 2021.

Caso da Comunidade Mayagna (Sumo) Awas Tingni vs. Nicarágua. Sentença de 31 de agosto de 2001. Disponível em: https://www.corteidh.or.cr/docs/casos/articulos/seriec_79_por.pdfAcesso em: 07 fev. 2021.

CIJ. Frontier Dispute (Burkina Faso/Niger). Judgment of 16 April 2013. Disponível em: https://www.icj-cij.org/en/case/149/judgments. Acesso em: o7 fev 2021.

Request for Interpretation of the Judgment of 15 June 1962 in the Case concerning the Temple of Preah Vihear (Cambodia v. Thailand). Judgment of 11 November 2013. Disponível em: https://www.icjcij.org/en/case/151/judgments. Acesso em: 07 fev. 2021.

COELHO, Fábio Alexandre; SPESSOTTO, Ricardo Zanetta (Orgs). Lei de Migração - Lei no 13.445, de 24 de maio de 2017. Bauru: Livraria Pessotto, 2017.

CONSULTOR JURÍDICO. Ministério da Justiça muda regras na lei de migração.

Conjur, São Paulo, 27 jul. 2013. Disponível em: 
Revista Brasileira de História \& Ciências Sociais - RBHCS

Vol. 13 No 26, Janeiro - Junho de 2021

<https://www.conjur.com.br/2013-jul-27/ministerio-justica-inicia-reformulacaolegislacao-migracao >. Acesso em: 28 jan. 2021.

CURY, Victor R.; DIAS, Eliotério F. Venezuela e o fluxo migratório de indígenas ao brasil: uma abordagem de direitos. Revista Jurídica Direito, Sociedade e Justiça, Dourados, v. 7, n. 1, Nov/2018-Jan./2019, p. 1-33

DUPAS, Elaine; BOTELHO, Tiago R. A nova Lei de Migração e a biopolítica: o veto à livre circulação de povos indígenas e populações tradicionais transfronteiriças. Teresina: Arquivo Jurídico, Teresina-PI, v. 4, n. 2, jul./dez. 2017, p. 72-89.

DUPAS, Elaine et. al. A nova Lei de Migração e o veto à livre circulação de povos indígenas e populações tradicionais transfronteiriças. In: XIV Congresso

Internacional de Direitos Humanos, UCDB e UFMS, 14-16 ago. 2017. Disponível em: <https://cidh2017.files.wordpress.com/2017/10/ar_gt2-4.pdf>. Acesso em: 03 fev. 2021.

FERRARI, Maristela. Zona de fronteira, ciudades gêmeas e interações transfronteiriças no contexto do MERCOSUL. Revista Transporte y Territorio, n. 9, p. 87-104, 11.

FRAZÃO, Samira Moratti. Política (i)migratória brasileira e a construção de um perfil de imigrante desejado: lugar de memória e impasses. Antíteses, v. 10, n. 20, pp. 1103-1128, jun/dez. 2018.

FUNAI. OEA aprova Declaração Americana sobre os Direitos dos Povos Indígenas. Fundação Nacional do Índio, [S.l.], 28 jun. 2016. Disponível em: $<$ http://www.funai.gov.br/index.php/comunicacao/noticias/3815-oea $>$. Acesso em: 05 fev. 2021.

GUERRA, Sidney. A nova lei de migração no Brasil: avanços e melhorias no campo dos direitos humanos. Revista de Direito da Cidade, v. 9, n. 4, 2017, p. 17171737. Disponível em: https://www.e-

publicacoes.uerj.br/index.php/rdc/article/view/28937/21967. Acesso em: 07 fev. 2021

GOMES, Joséli F. Nova Lei de Migração brasileira: análise dos avanços face ao Estatuto do Estrangeiro e das dificuldades postas pelos vetos presidenciais. In: Questões de Direito Internacional: pessoa, comércio e procedimento II [livro eletrônico]. / Frederico Eduardo Zenedin (coord.). Curitiba: Editora JML, 2018. P. 9-33.

KENICKE, Pedro Henrique G. O Estatuto do Estrangeiro e a Lei de Migrações: entre a doutrina da segurança nacional e o desenvolvimento humano. Curitiba: Universidade Federal do Paraná, 2016. 
Revista Brasileira de História \& Ciências Sociais - RBHCS

Vol. 13 No 26, Janeiro - Junho de 2021

MACHADO, Vagner G.; et. al. Migración Warao en Brasil: consideraciones sobre la participación de la autoridad nacional indigenista en la respuesta y amparo a la comunidad indígena inmigrante. In: CAMARDELO. Ana Maria Paim; SILVEIRA. Clóvis Eduardo Malinverni da; MACHADO. Vagner Gomes. Derechos humanos y crisis ambiental en iberoamérica: volumen 1. Lages/SC: Editora Biosfera, 2020. P. 227-261

MARÉCHAL, Clémentine; VELHO, Augusto Leal de Britto; RODRIGUES, Milena Weber; BUENO, Pietro. Transformações sociais e (re)territorialização Warao no Brasil: a trajetória de uma família frente à pandemia de covid-19. Espaço Ameríndio, Porto Alegre, v. 14, n. 2, jul./dez. 2020, p. 46-87.

MERGULHÃO, Alfredo. Justiça de Roraima impede deportação imediata de 55 indígenas venezuelanos. Revista Época, [S.l.], o9 jan. 2021. Disponível em: $<$ https://epoca.globo.com/brasil/justica-de-roraima-impede-deportacao-imediatade-55-indigenas-venezuelanos-24830475>. Acesso em: 05 fev. 2021.

MPF. Parecer técnico $n^{0}$ 10/2017 - SP/MANAUS/SEAP. Parecer Técnico acerca da situação dos indígenas da etnia Warao na cidade de Manaus, provenientes da região do delta do Orinoco, na Venezuela. Ministério Público Federal do Amazonas, Manaus, 2017.52p. Disponível em: <http://www.mpf.mp.br/am/sala-de-imprensa/docs/parecer-tecnico-warao>. Acesso em: 05 fev. 2021.

NAÇÕES UNIDAS. Declaração das Nações Unidas sobre os Direitos dos povos indígenas. Povos Indigenas no Brasil, [S.l.], 13 set. 2007. Disponível em: <https://pib.socioambiental.org/files/file/PIB_institucional/DECLARACAO_DAS _NACOES_UNIDAS_SOBRE_OS_DIREITOS_DOS_POVOS_INDiGENAS.pdf $>$. Acesso em: 03 fev. 2021.

OAS. Declaração de Cartagena. Cartagena das ìndias, 22 de novembro de 1984. Disponível em: https://www.acnur.org/fileadmin/Documentos/portugues/BD_Legal/Instrumentos_ Internacionais/Declaracao_de_Cartagena.pdf. Acesso em: 07 fev. 2021

OIM, Organização Internacional para as Migrações. Aspectos jurídicos da atenção aos indígenas migrantes da Venezuela para o Brasil. IOM Brazil, Brasília, 2018. Disponível em: < https://publications.iom.int/books/aspectos-juridicos-da-atencaoaos-indigenas-migrantes-da-venezuela-para-o-brasil>. Acesso em: 03 fev. 2021.

. Soluções duradouras para indígenas migrantes e refugiados no contexto do fluxo venezuelano no Brasil. Elaine Moreira, Marcelo Torelly (coord.). Brasília: Organização Internacional para as Migrações (OIM), 2020. 110p. ISBN 97865-87187-00-6.

PARAIZO, Lucas. Após impasse entre prefeitos, venezuelanos enviados para Florianópolis voltam a Itajaí. NSC Total, Florianópolis, 24 dez. 2019. Disponível em: 
Revista Brasileira de História \& Ciências Sociais - RBHCS

Vol. 13 No 26, Janeiro - Junho de 2021

https://www.nsctotal.com.br/noticias/apos-impasse-entre-prefeitos-venezuelanosenviados-para-florianopolis-voltam-a-itajai

PARENTE, Marília. No Recife, 73 venezuelanos vivem aglomerados em duas casas. Leia Já, Recife, 06 nov. 2019. Disponível em: https://www.leiaja.com/noticias/2019/11/o6/no-recife-73-venezuelanos-vivemaglomerados-em-duas-casas/. Acesso em: 07 fev. 2021

PEREIRA, André Paulo. O povo indígena Warao: um caso de imigração para o Brasil. Conjur, São Paulo, 21 jan. 2019. Disponível em: https://www.conjur.com.br/2019jan-21/mp-debate-povo-indigena-warao-imigracao-brasil\#_ftn1. Acesso em: 06 fev. 2021

POVOS INDÍGENAS NO BRASIL. Taurepang. Povos Indígenas no Brasil, publicado em dez. 2004. [S.l.]. Disponível em:

<https://pib.socioambiental.org/pt/Povo:Taurepang>. Acesso em: 05 fev. 2021.

R4V. Plataforma de Coordinación para Refugiados y Migrantes de Venezuela. R4V - Respuesta a los Venezolanos. Atualizado em 05 jan. 2021. Disponível em: <https://r4v.info/es/situations/platform>. Acesso em: 04 fev. 2021.

RODRIGUES, Marco A.; RODRIGUES, Andréa C.; URQUIZA, Antonio A. Ñande $\mathrm{Ru}$ Marangatu e a mensagem de veto $\mathrm{n}^{\circ} 163 / 2017$. Revista Digital Constituição e Garantia de Direitos, v. 12, n. 1, set. 2019, p. 109-133.

SEMINARIO online debate presença de inígenas Warao no Maranhão. O Estado, São Luís, 11 ago. 2020. Disponível em:

https://imirante.com/oestadoma/noticias/2020/08/11/seminario-online-debatepresenca-de-indigenas-warao-no-maranhao/. Acesso em: 07 fev. 2021.

SESTOKAS, Lucia. Apesar de vetos, nova Lei de Migração é um avanço para migrantes no Brasil. Entrevista a Nana Soares. Portal Aprendiz, [S.l.], 02 jun. 2017. Disponível em: <https://portal.aprendiz.uol.com.br/2017/06/o2/apesar-devetos-nova-lei-da-migracao-e-um-avanco-para-migrantes-brasil/>. Acesso em: 04 fev. 2021.

SEYFERTH, Giralda. Colonização, imigração e a questão racial no Brasil. Revista USP, São Paulo, n. 53, p. 117-149, março/maio 2002.

SILVA, Rodolfo Ilário da. Transnacionalidade: Um fator essencial para a compreensão dos povos indígenas e de sua atuação na política global. Boletim Meridiano 47, Brasília, v. 14, n. 138, jul./ago. 2013, p. 23-2

SIMONI, Rafael L.; VEDOVATO, Luis Renato. A migração fronteiriça no Brasil: os desafios da nova lei de migrações, vetos e regulamento. In: BEANINGER, Rosana; CANALES, Alejandro. (Orgs.). Migrações Fronteiriças. Campinas/SP:

NEPO/Unicamp, 2018, p. 304-313. Disponível em: 
Revista Brasileira de História \& Ciências Sociais - RBHCS

Vol. 13 No 26, Janeiro - Junho de 2021

https://brazil.iom.int/sites/default/files/Publications/mig_fronteiricas.pdf. Acesso em: 07 fev. 2021

SIMÕES, Gustavo da Frota. Perfil sociodemográfico e laboral da imigração venezuelana no Brasil. Curitiba: CRV, 2017.

SILVEIRA, Marina P; CARNEIRO, Cynthia S. A declaração das nações unidas sobre os direitos dos povos indígenas e os impactos da nova lei de migração brasileira sobre o direito de livre circulação do povo Warao. Périplos: Revista De Estudos Sobre Migrações, v. 2, n. 2, pp. 69-95, 2018. Disponível em: https://periodicos.unb.br/index.php/obmigra_periplos/article/view/25459. Acesso em: 07 fev. 2021.

SOUSA, Julia Henriques. Janokos brasileiros: uma análise da imigração dos Warao para o Brasil. Boletim Científico ESMPU, Brasília, a. 17 - n. 52, p. 71-99 jul./dez. 2018

SQUEFF, Tatiana Cardoso. Migrações em tempos líquidos e a postura (positiva) brasileira frente ao êxodo venezuelano. In: PALUMA, Thiago; SQUEFF, Tatiana Cardoso (Org.). Migração internacional no século XXI: perspectivas e desafios. Belo Horizonte: Arraes Editores, 2019. p. 117-143.

. Estado Plurinacional: a proteção do indígena em torno da construção da hidrelétrica de Belo Monte. Curitiba: Juruá, 2016.

; MONTEIRO, Michelle Alves. Multiculturalism and Human Rigths in indigenous traditional practices: a brief analisys from the Brazilian Law Project $\mathrm{n}^{\mathrm{o}}$ 1.057/07. Revista Direito UFMS, v. 4, n. 2, 2018.

TRINDADE, Antônio Augusto Cançado. "Acima dos Estados estão os seres humanos que os compõem”. Entrevista concedida a Pablo X. de Sandoval. El País, Madri, 01 abr. 2014. Disponível:

<https://brasil.elpais.com/brasil/2014/o3/31/internacional/1396300ooo_175731. html>. Acesso em: 03 fev. 2021.

UNHCR. Minorities and Indigenous Peoples. UNHCR, The UN Refugee Agency, [S.d.]. Disponível em: <https://www.unhcr.org/minorities-and-indigenouspeoples $>$. Acesso em: 05 fev. 2021.

VEDOVATO, Luís R.; ASSIS, Ana Elisa S. Q. Os vetos à nova Lei de Migração brasileira. A interpretação como um passo necessário. In: BAENINGER, R. et. al. (Orgs.). Migrações Sul-Sul. Campinas, Núcleo de Estudos de População "Elza Berquó" - Nepo/Unicamp, 2018, p. 597-608.

VENTURA, Deisy; ILLES, Paulo. Qual a política migratória do Brasil? Le Monde Diplomatique Brasil, [S.l.], 07 mar. 2012. Disponível em: $<$ https://diplomatique.org.br/qual-a-politica-migratoria-do- 
Revista Brasileira de História \& Ciências Sociais - RBHCS

Vol. 13 No 26, Janeiro - Junho de 2021

brasil/\#: :text=Migrar\%20\%C3\%A9\%20um\%2odireito\%2ohumano,vezes\%20at\% C3\%A9\%20em\%20nossa\%20p\%C3\%A1tria.>. Acesso em: 16 jan. 2021.

VIEIRA, Aline. Após conflito com governo, indígenas venezuelanos deixam abrigo no AC e voltam para prédio abandonado. G1, Rio Branco, 16 abr. 2020. Disponível em: https://g1.globo.com/ac/acre/noticia/2020/04/16/apos-conflito-comgoverno-indigenas-venezuelanos-deixam-abrigo-no-ac-e-voltam-para-predioabandonado.ghtml. Acesso em: 07 fev. 2021

YAMADA, Erika. Veto na Lei de Imigração aumenta a criminalização de indígenas. Carta Capital, [S.l.], 26 mai. 2017a. Disponível em:

$<$ https://www.cartacapital.com.br/sociedade/veto-na-lei-de-imigracao-aumentaa-criminalizacao-de-indigenas/>. Acesso em: 16 jan. 2021.

. Brasil é cobrado na ONU por retrocesso nos direitos indígenas. Carta Capital, [S.l.], o8 mai. 2017b. Disponível em: < https://www.cartacapital.com.br/sociedade/reivindicacoes-do-brasil-indigenaretratadas-na-onu/>. Acesso em: 03 fev. 2021.

; et al. Aspectos jurídicos da atenção aos indígenas migrantes da Venezuela para o Brasil. Brasília: Organização Internacional Para As Migrações - Brasil, 2018. 136 p. Disponível em: <https://www.refworld.org.es/pdfid/5b2044684.pdf>. Acesso em: 05 fev. 2021.

WERMUTH, Maiquel A. D. A Lei 13.445/207 e a ruptura paradigmática rumo à proteção dos Direitos Humanos dos migrantes no Brasil: avanços e retrocessos. In: Nova Lei de Migração: os três primeiros anos. André Carvalho de Ramos; Luís Renato Vedovato; Rosana Baeninger (Coord.). Campinas: Núcleo de Estudos de População "Elza Berquó" - Nepo; Unicamp - Observatório das Migrações em São Paulo/FADISP, 2020, p. 101-116. 